\title{
GEOMETRIC INEQUALITIES INVOLVING TWO SIMPLEXES
}

\author{
YANG SHIGUO
}

Abstract. We estabish some geometric inequalities on the inradius and circumradius of two $n$-dimensional simplexes.

Mathematics subject classification (2000): 52A40.

Key words and phrases: simplex, volume, inradius, circumradius.

\section{REFERENCES}

[1] Leng Gangsong, Some inequalities involving two simplexes, Geom. Dediceta 66 (1997), 89-98.

[2] M. S. KLAMKIN, Inequality for a simplex, SIAM. Rev. 27 (4) (1985).

[3] D. S. Mitrinović, J. E. PEČArić AnD V. Volenec, Recent advances in geometric inequalities, Kluwe Acad. Publ., Dordrecht, Boston, London, 1989.

[4] D. S. Mitrinović, Analytic inequalities, Springer-Verlag, Berlin, Heideberg, New York, 1970.

[5] F. ERIKSSON, The law of sines for tetrahedra and n-simplexes, Geom. Dedicata 7 (1978), 71-80.

[6] Yang SHIGUO AND WANG JiA, An inequality for $n$-dimensional sines of vertex angles of a simplex with some applications, J. Geom. 54 (1995), 198-202.

[7] YANG SHIGUO, Some inequalities on areas of bisection planes of dihedral angles of a simplex, Geom. Dedicata 62 (1996), 161-165.

[8] ZHANG HANFAN, The high-dimensional generality and improvement of a geometic inequality, (in Chinese), J. of Xuzhou Teachers College 14 (1996), 11-14. 